Article

\title{
The Resilience of Sustainability Transitions
}

\author{
Thorsten Schilling *, Romano Wyss $₫$ and Claudia R. Binder ( \\ Laboratory for Human Environment Relations in Urban Systems (HERUS), Swiss Mobiliar Chair in Urban \\ Ecology and Sustainable Living, Institute of Environmental Engineering (IIE), School of Architecture, Civil and \\ Environmental Engineering (ENAC), École Polytechnique Fédérale de Lausanne (EPFL), CH-1015 Lausanne, \\ Switzerland; romano.wyss@epfl.ch (R.W.); claudia.binder@epfl.ch (C.R.B.) \\ * Correspondence: thorsten.schilling@epfl.ch; Tel.: +41-21-69-33767
}

Received: 25 October 2018; Accepted: 30 November 2018; Published: 5 December 2018

\begin{abstract}
Finding ways to understand, analyze, and manage sustainability transitions is a fundamental challenge for sustainability science. In this paper, we show how we can substantially deepen our understanding of factors that determine the success of sustainability transitions by combining two key concepts from the resilience literature-stability and adaptability-with a dynamic understanding of the progress of socio-technical transitions. We propose a conceptual perspective for sustainability transitions, the resilience of sustainability transitions (RST) concept, which integrates progress, stability, and adaptability as key dimensions to comprehend the dynamics of sustainability transitions. In a case analysis of the energy transition process in the Austrian region of Weiz-Gleisdorf, we apply the concept. In doing so, we illustrate how RST thinking helps identify and understand crucial elements that influence the dynamics of a sustainability transition process.
\end{abstract}

Keywords: sustainability; transitions; resilience; energy

\section{Introduction: Understanding Sustainability Transitions}

Transitioning toward more sustainable living, working, and pursuit of leisure activities is a central challenge of our time. Despite the many initiatives on a national and international level to work toward increased sustainability, and reducing the global footprint of our societies, the actual trend continues to show accelerating global demand for natural resources linked to water, land, and energy consumption, and persisting social and economic inequality [1-3].

In the sustainability science discourse, sustainability transitions have been coined as purposive transitions associated with sustainability goals [4]. Thereby, sustainability transitions can be defined as "long-term, multi-dimensional, and fundamental transformation processes through which established socio-technical systems shift to more sustainable modes of production and consumption" [5] (p. 956). The aim of sustainability transitions is to enhance a system's overall sustainability, e.g., by means of technological, social, or political interventions [4,6,7]. Sustainability transitions differ in many aspects from other historical socio-technical transition processes. At the core of sustainability transitions lies the goal to create a more sustainable system state, which results in a strongly normative and goal-oriented perspective [8]. Different scholars have highlighted that transitions toward sustainability require changes not only in technology, but also in our societal structures, routines, and cultural practices $[5,9]$. Such changes must be managed and integrated, informed by interdisciplinary scientific approaches that consider the interactions between social, ecological, and technical subsystems [10-14]. With broad agreement on the policy side that transitioning toward a more sustainable society is desirable, the need to understand when and why sustainability transitions succeed or fail has become of paramount importance [15]. For this purpose, a comprehensive and holistic theoretical perspective on sustainability transitions is necessary. 
Transitions and resilience thinking each provide their own distinct theoretical view on how societal systems can reach a more sustainable state $[5,14,16]$. The key strands of transition studies (transition management, strategic niche management, multi-level perspective, technological innovation systems; see Markard et al. [5] for an overview) and more recent contributions, such as Geel's Triple Embededness Framework [17], share the primary ambition to understand the progress of transition dynamics as a result of the interplay between innovation and resistance on a systemic level. Resilience scholars primarily focus on dynamic equilibria, i.e., relatively stable system states that are able to withstand external shocks or disturbances [18]. Thereby, transformation (fast, radical change) and adaptation (slow, incremental change) are two processes through which the system can reach alternative, more sustainable dynamic equilibria [19]. In this context, the resilience of a system state is commonly defined as "the capacity of a system to absorb disturbance and reorganize while undergoing change so as to still retain essentially the same function, structure, identity, and feedbacks" [20] (p. 6).

Some scholars identified the added-value of linking a transitions and resilience view on sustainability transitions and provided first ideas for a combined perspective [14,21-24]. This includes a stronger emphasis on social-ecological transformations in the resilience discourse [25-27] as well as the need to consider a common system's perspective by integrating ecological aspects in transition studies [9] and vice versa by applying a stronger focus on the role of technology and innovation in resilience research [28].

Binder et al. [13] addressed the resilience of systems in transition, concluding that systems have to maintain their functionality throughout the transition process in order for the transition to be successful. Ideally, the system in transition has to be resilient to external and internal shocks and challenges throughout the transitions process. To further advance the endeavor to link transitions and resilience perspectives, Olsson et al. [22] concluded with the development of a sustainability transition theory that integrates resilience and transitions thinking and embraces a broad and comprehensive perspective on sustainability transitions.

The goal of this paper was to provide a theoretical concept that helps to understand the dimensions affecting the success of sustainability transitions. Thereby, we (1) integrate resilience and transitions thinking, (2) elaborate distinct analytical perspectives to understand the dynamics of a sustainability transition, and (3) verify our concepts against a case study and illustrate the benefits of a resilience of sustainability transitions (RST)-based analysis with the case of an energy transition

\section{Theoretical Background}

The transitions literature offers many conceptual approaches for the analysis of long-term societal transition processes that aim at "society-wide change that goes beyond single sectors and involves fundamental and interrelated changes in technology, organizations, institutions and culture" [29] (p. 81). Loorbach et al. [14] and Markard et al. [5] both comprehensively provided an overview of the field and defined the fundamental characteristics of the main strands of thought within the transitions community.

The majority of transition studies addressed the dialectic between innovative activities fostering change (niches) and the dominant configurations that stabilize the current system state (regime resistance) [30-34]. Transitions in socio-technical systems are often preceded by incremental developments in technical or social niches, whereby the "growing out" of the niche represents a major development threshold [8,35]. Existing barriers to change from the dominant socio-technical regime, such as sunk investments in old technologies or institutional routines, can work against the growing out of the niche and act as regime resistance. Trends, developments, and sudden events in the context of the system can exert pressure on the system and open up opportunities for the break-through of niche innovations [36,37]. To describe the context of the system, transition scholars refer to a landscape metaphor. "The sociotechnical landscape is a landscape in the literal sense, something around us that we can travel through; and in a metaphorical sense, something that we are part of, that sustains us" [38] (p. 334). The socio-technical landscape does not determine change directly, but provides "deep structural 'gradients of force' that 
makes some actions easier than others" [37] (p. 403). In this sense, sustainability—once it is established as a guiding norm for societal development—can become such a deep structural gradient of force that facilitates actions toward sustainability than in unsustainable directions.

This understanding of socio-technical landscapes corresponds to the "stability landscape" concept proposed in the resilience literature by Walker et al. [20]. The topography of the stability landscape determines the ease or difficulty of changing the current system state in a specific direction. As such, "basins of attraction" represent system states within which resilient systems operate. The resilience of a system is characterized by four key-indicators: (1) latitude, relating to the degree of system change that is possible without losing the ability to recover; (2) resistance, signifying the ease or difficulty of changing the system; (3) precariousness, representing the distance between the current system state and the critical threshold at which the system can no longer recover (the smaller the distance, the more likely it is that the critical threshold will be crossed); and (4) panarchy, describing the influence of cross-scale interactions with systems at scales above and below the system $[18,39]$. This consideration of cross-scale interactions-most prominently elaborated in Gunderson and Hollings research on panarchy [39] - is another common denominator between transitions and resilience thinking.

\section{Methods}

The starting point for the development of the resilience of sustainability transitions (RST) concept is a re-entry approach [40]. This method seeks to transcend existing boundaries and ways of thinking by re-introducing concepts back to themselves and creating a meta-perspective. A re-entry for the concept of sustainability transitions leads to the question, "what is the transition of the sustainability transition?". Following this line of thought, we focused on the development and the dynamics of the sustainability transition process itself. To identify the aspects that affect the success of a sustainability transition process, we then proceeded by reflecting on and integrating ideas from the (sustainability) transitions and (socio-ecological) resilience literature. This approach follows the call by Kerssens-van Drongelen [41] for iterative theory-building. We referred to the resilience of a sustainability transition as the sum of factors that determine the dynamics of such a sustainability transition process. To derive the respective factors, we critically reflected on theoretical insights from transition and resilience thinking and combined the core aspects in an integrated theoretical concept. In doing so, we identified and elaborated upon three key dimensions for the RST concept: progress, stability, and adaptability. We focused on these three dimensions because they allowed us to represent the essence of transitions and resilience thinking without compromising the other perspectives in the integration process. Transition progress builds the foundation and the starting point of the development of the RST concept. In this dimension, we primarily collected theoretical insights from transition concepts that address the dialectic between innovative activities (drivers) and regime resistance. Understanding different constellations of transition progress (drivers vs. resistance) is key to determining whether and how a system transforms toward sustainability. In this regard, a sustainability transition that stops proceeding can no longer be resilient and fails.

We built upon this basic understanding of transition progress and complemented it with two additional layers: stability and adaptability. These are at the core of resilience thinking and allowed us to understand when and why system states persist in an uncertain and volatile environment. Stability determines the reaction to shocks and disturbances and adaptability the capacity of system actors to manage and adapt the system. We transferred these ideas and integrated them into the RST concept as characteristics of a transition process. Due to the typically long time-span of sustainability transition processes, it is likely that unforeseen events, such as shocks or opportunities, emerge while the transition is ongoing. Such situations can become critical for the outcome of a sustainability transition process. Considering the stability and adaptability allowed us to further differentiate and understand the state of a transition process with regard to how stable and adaptive it is in facing uncertainty. We further elaborate the dimensions in the sections below (Sections 4.2-4.4) and provide short summaries in Tables 1-3. 
By drawing on the three key dimensions transition progress, stability and adaptability, we illustrate how the RST concept can be used for the analysis of an energy transition process.

We built upon these three key dimensions to analyze an energy transition process in an Austrian energy region. We built on previously published work by the authors in the Energy Region Weiz-Gleisdorf (EWG) $[13,42,43]$. Interviews with central actors of the energy transition were carried out in the region in 2011,2016, and 2017, including a personal visit to one of the authors in the region in 2016. Overall, 13 interviews were conducted in 2011, 9 interviews in 2016, and 3 telephone interviews to specify technical details in 2017. A core group of 5 interviewees were identified together with the manager of the steering body of the energy region. The selection of the further interview partners occurred in a snowball-sampling process

Working with a semi-structured interview approach, information on actor networks, transition drivers and barriers, as well as crucial milestones in the regional energy transition was collected. Specific insights into the development of the technical infrastructure (grid, production entities) were gathered. In order to better understand the perceived dynamics of the transitions process, mental models of core actors in the system on their perception of the system transition were recorded. These models were derived in the course of a ca. $1 \mathrm{~h}$ discussion. Following a cognitive mapping approach [44], representations of who the central actors were at three distinct points in time (1996, 2011, and 2016) were gathered. The interviewees then had to lay out on an A4 piece of paper how central the individual actors were with respect to the governance of the energy transition, and how close they were one to another with respect to the implementation of measures driving the transition. This mixed-methods approach allowed us to shed light on both the technological developments in the energy production and distribution system as well as on the socio-political and economic governance structure of the EWG region.

Based on this previously published material, we revised the empirical data and applied the RST dimensions as analytical lenses for the existing empirical material. This allowed us to filter all insights on the dynamic development of the transition process from the data, upon which we built our analysis. We present the results from the case analysis after each RST concept subsection.

Eventually, we combined theoretical and empirical insights to propose a set of factors that could be a starting point for an RST-based analysis of sustainability transition processes (Appendix A). The resulting table contains three sections: the RST dimensions and the respective analytical perspectives mirror the theoretical part of the paper. The RST factors are a non-hierarchical compilation of operationalizations that we developed based on our experiences with the empirical application. The RST factors are supposed to be sufficiently general to be applicable in a wide variety of contexts, while simultaneously being concrete enough to be useful without a thorough and deep understanding of the underlying theoretical assumptions.

\section{Results: The Resilience of Sustainability Transitions (RST) Concept}

\subsection{Sustainability Transitions from a Stability Landscape Perspective}

We use the stability landscape metaphor to illustrate a resilient sustainability transition [20]. This ideal-typical picture of a transition process includes two basins of attraction that are connected by a transition pathway. One basin represents the current, unsustainable system state and the other represents the goal system state with a higher sustainability (Figure 1). The distance between both states indicates how much they vary from each other. Besides the distance, we need to consider the topography of the stability landscape within which the two basins are embedded, i.e., the shape of the two basins and of the pathway(s) connecting them. The topography of the stability landscape represents all factors (system internal and external) that determine how easy or difficult it is to move the system in a specific direction. 


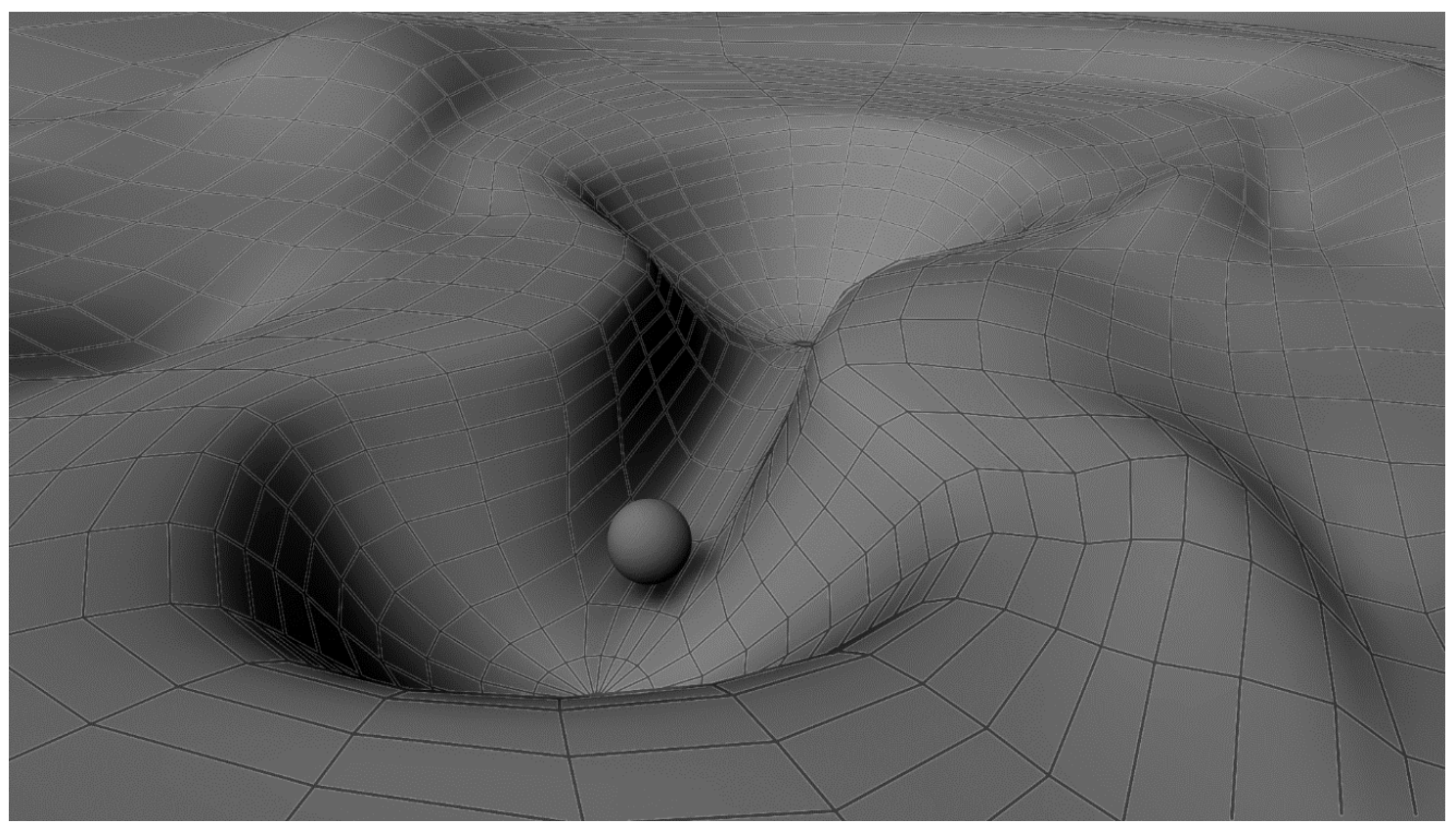

Figure 1. Ideal-typical illustration of a sustainability transition process from a stability landscape perspective.

Figure 1 shows how a stainability transition could ideal-typically look. The ball (system) rolls (transforms) out of the center of a relatively stable basin of attraction (unsustainable system state) through a relatively stable "halfpipe of attraction" (transition pathway) toward an alternative basin of attraction (more sustainable system state). The halfpipe's shape represents-an analogy to the original stability landscape definitions - the resistance (depth) of the pathway, i.e., the ease or difficulty to deviate from the pathway, and its flexibility, i.e., the amount of deviation that is possible without losing the ability to recover to the original orientation (width). We combined both aspects to define the overall stability of a transition pathway.

This stability landscape-based understanding allows the differentiation between resilient system states, which exclusively depend on the current basin of attraction, and resilient transition processes, which depend on the current basin of attraction, the alternative basin of attraction, the halfpipe of attraction, and the transition progress over time. We built upon this dynamic stability landscape logic to integrate ideas from transitions thinking (transition progress) with resilience thinking (stability and adaptability). We adopted the key features of the above-stated resilience definition by Walker et al. [20], and define the resilience of a sustainability transition process as the capacity of a system to absorb disturbance and adapt the sustainability transition process to still essentially retain its progress, goals, and pathway. In other words, the resilience of a sustainability transition determines whether the system is capable of successfully going through a sustainability transition process and eventually reaching a higher state of sustainability. This capacity depends on various factors that shape the progress, stability, and adaptability of the sustainability transition process.

Case explanation: EWG is a climate and energy model region located in Styria, Austria. It spans 18 communities with a population of around 42,000. First initiatives to shift regional energy production toward renewables emerged at the end of the 1980s. The development was backed by the federal funding scheme for climate and energy regions ("Klima-und Energieregionen") in Austria, which was introduced in the 1990s, which allowed the region to gain official status as an energy region in 1996. Besides being a labelled energy region, EWG is also an EU "LEADER" region since 2007 and an Austrian "smart region" since 2011. 


\subsection{Transition Progress}

Transition progress depends on the impact of the actions taken by individuals and groups to change the structure and functions that define the current state of the system [9]. A sustainability transition is, per definition, a dynamic change process [14]. Its most fundamental characteristic is the degree to which a system transforms in a specific period of time [45]. This degree depends on two aspects: drivers for system change and resistance against system change. Defining transition progress, as the first RST dimension, enabled us to consider the quantity (how much does the system change over a specific period of time?) and quality (is the change process radical and disruptive or incremental and smooth?) of system change during a sustainability transition process.

\subsubsection{Drivers}

We define a transition driver as an innovation that causes system state changes and thus affects the transition progress. This includes technical and social innovations, such as the break-through of a technical artifact, cooperation between actors, economic investments, social movements, or political interventions. Transition drivers can vary in terms of their direction of influence (different drivers can work in diverging directions). For sustainability transitions, a driver can either contribute to reaching a set sustainability goal or can move the system toward a less sustainable state. Furthermore, transition drivers can differ in the quality of the impact they have on the transition progress. One transition driver might change the system state more fundamentally, whereas another only has a small, incremental effect.

Scholars from the field of transition management or strategic niche management specifically focus on protected spaces in so-called niches, in which highly creative actors can experiment and come up with new ideas and innovations that eventually become transition drivers [14,46-48]. They identify the creation of niches and the support of highly creative pioneers as a crucial success factors for the progress of transitions. Therefore, it is essential that highly creative pioneers exist in the system and that the governance system prioritizes supporting innovative activities and developments. This applies as well to the context of companies and non-government organizations (NGOs). Depending on the strategies and mindsets behind these organizations, more or less potential might exist for innovation, which can lead to the creation of transition drivers.

In the stability landscape metaphor, transition drivers act as the "fuel" that moves the ball through the halfpipe of attraction. In doing so, they affect the relative distance between the current system state and the goal system state. Given the same landscape topography, more transition drivers would lead to more transition progress over a specific time.

Case explanation: In EWG, the vision of a region, in which energy production should be mainly based on renewables, was jointly developed by a core of actors in the region from the end of the 1980s onward. The first group of technologically interested people who drove the transition toward renewable energy sources gathered in the town of Gleisdorf (Styria) around Mr. Selvicka, who is today (2018) deputy director of the main sustainability research institute in the region. Their main goal was to develop and support the propagation of solar thermal installations for home use. This core of actors-engaged mainly on a voluntary basis—-was the source of the impulse in the area toward activities of renewable energy production. The group around Mr. Selvicka brought together interested people, organized workshops, financial support, and, ultimately, at the beginning of the 1990s, founded the "AEE Intec" research institute.

Although the main driver for the engagement of this core group of actors was their technical curiosity and interest, the transition soon gained momentum as central political actors, mainly the mayors of the towns of Gleisdorf and Wei, as well as the representatives of the two regional utilities companies and the CEO of a major engine plant in the region, joined and made renewable energy production one of their core strategic interests. A central figure in driving the process was Mr. Nussbaumer who was simultaneously the mayor of the town of Gleisdorf and the director of the 
utility company in the Weiz. He supported the activities in the field of renewable energies in the region, both ideologically as well as financially, for over 20 years.

\subsubsection{Resistance}

Whether a newly emerging idea will contribute successfully to the progress of the transitions also depends on existing resistance against system change. Resistance in the dominant regime can reduce the impact of transition drivers on the progress of the transition. This applies, for example, if compromises in political decision-making processes lead to results that are suboptimal for sustainability. Then, a political sustainability intervention might not reach its full potential. Resistance hinders the emergence of innovative ideas. The creative potential of pioneers or change agents is limited if conservative system structures do not support the establishment of socio-technical niches in which they can operate and experiment.

Resistance can have many forms and motivations. On an individual level, system actors can apply various forms of power, such as political or financial power, to resist system transformation [33]. This becomes particularly critical for the transition progress, especially if power is paired with conservative mindsets and rigid inflexible networks [49]. In an economic context, costs (in its broadest meaning) related to change also play a role. The introduction of a new technology, for example, is associated with overcoming old routines and the need to learn new skills, which requires a certain effort from the affected actors. Costs can emerge in the governance system if new system constellations do not align well with existing rules and regulations that then need to be adapted to suit new developments.

Managing resistance is crucial for a sustainability transition to be successful. In the transition management literature, "phasing out" strategies are proposed to create smooth, non-disruptive processes of transformation that minimize negative consequences for incumbent system actors while ensuring transition progress [31]. These approaches aim to reduce resistance against a specific direction of transformation (e.g., sustainability) without generally destabilizing the existing regime.

Resistance appears as uphill parts in the stability landscape. Reducing resistance for a specific direction of transformation allows the creation of a "halfpipe of attraction", and consequently a non-disruptive, yet progressing, transition process.

Case explanation: Whereas the general support for the energy transition in the region was provided throughout the examined period from the end of the 1980s through to 2016, there was some major resistance in recent years in terms of the necessary engagement of individual actors. Individual households in the region are reluctant to invest in renewable energy installations mainly given the low price of conventional energy carriers. There is still major resistance to invest in state-of-the-art insolation and to change individual mobility patterns in favor of more energy friendly transportation modes, such as trains and electrical vehicles. Additionally, the regional energy transition is still lacking the support of the main international firms located in EWG, who are major energy consumers in the region. Due to the lack of engagement by these large commercial energy consumers, system-wide synergies, such as using waste heat to fire district heating networks or adapting industrial processes in order to make use of excess energy supply, are not yet sufficiently developed (Table 1). 
Table 1. Transition progress.

\begin{tabular}{ccccc}
\hline $\begin{array}{c}\text { Resilience of Sustainability } \\
\text { Transition (RST) Dimension }\end{array}$ & Analytical Perspective & Relevance for Sustainability Transitions & Stability Landscape Metaphor & Main Aspects in the Energy Region \\
\hline Transition progress & Drivers & $\begin{array}{l}\text { Transition drivers affect the system state by } \\
\text { changing its structure or functionality. }\end{array}$ & $\begin{array}{l}\text { Transition drivers affect the distance } \\
\text { between the current system state and } \\
\text { the envisioned system state. }\end{array}$ & $\begin{array}{l}\text { Core group of motivated innovators. } \\
\text { up structures and initiating projects. } \\
\text { Funding opportunities from state-level, national and } \\
\text { EU-sources. }\end{array}$ \\
\cline { 2 - 5 } & Resistance & $\begin{array}{l}\text { Resistance is the counterpart of transition } \\
\text { drivers. Resistance can negatively affect } \\
\text { the sustainability transition progress by } \\
\text { slowing it down or even prevent it. }\end{array}$ & $\begin{array}{l}\text { Resistance appears as uphill parts in } \\
\text { the envisioned transition pathway } \\
\text { (halfpipe of attraction). }\end{array}$ & $\begin{array}{l}\text { Individual households and large commercial consumers are } \\
\text { not willing to engage. } \\
\text { Synergies between industry, urban utilities, and consumers } \\
\text { are not developed sufficiently. }\end{array}$ \\
\hline
\end{tabular}




\subsection{Stability}

Stability is the second dimension we addressed within the RST concept. It is related to the system actors' capacity to deal with uncertainty, react to unforeseen events, and recover from shocks, while maintaining the sustainability transition process. Sustainability transitions are goal-oriented and thus highly normative processes that mostly occur in an uncertain and unpredictable environment and can last for long timespans [9]. They are exposed to several unforeseeable events and risks during the transition process that might cause redirections of the transition pathway away from its original sustainability goals or even endanger the transition process as a whole. Therefore, it is crucial to consider aspects that stabilize the sustainability transition process. In doing so, these aspects enable the transition process to persist in an uncertain and volatile environment and recover from shocks without losing its original orientation toward sustainability.

\subsubsection{Stability of the Sustainability Transition Process}

We identified two major aspects of a sustainability transition process that affect its overall stability: (1) the stability of the envisioned system state with the corresponding sustainability goals and (2) the stability of the transition pathway that is supposed to lead to the envisioned state.

The stability of the envisioned system state is closely connected to its level of attraction, which depends on various variables, such as the specificity of the goals set, the clarity and outreach of its communication toward system actors, the perceived advantages of the envisioned system state compared to the current state, and the general acceptance of the vision [50-53]. If sustainability is the dominant guiding norm for a transition, system actors need to agree on what sustainability means in the context of their system, develop sustainability goals, and create an understanding of the issues that need to be addressed accordingly. A commonly elaborated vision of the goal system state that is widely agreed upon within the system can exert a significant amount of attraction and stabilize the sustainability transition process [42,52]. In uncertain and turbulent phases of the transition, a strong vision can help to re-focus on the original goals. This applies especially when there is strong commitment among powerful system actors or even a formal agreement regarding the envisioned system state [53]. System actors invest in this vision emotionally through identification processes and materially by re-directing financial flows or making decisions that guide the system toward the goal system state. Consequently, the vision of the goal system state stabilizes, which makes deviation more difficult.

Different transition pathways can vary in terms of how they affect the stability of the transition process. Pathways can differ in the degree of resistance they imply toward the envisioned system state (Section 4.2.2), but also in terms of stability when facing unforeseen events. When changing boundary conditions, such as disadvantageous political or market developments, lead to unfulfilled expectations or general insecurity, the transition runs the risk of losing support from system actors that might look for alternative pathways. Pathway stability is crucial to minimize this risk and keep the transition on track. To stabilize a transition pathway, broad support for the sustainability transition is needed within the governance system and among the system actors in general. The governance system plays an important role in communicating and enabling transparent, reliable, and consistent boundary conditions for the transition process that remain stable over time [54]. This corresponds to a transition pathway that avoids disruptive, sudden, and radical changes in the system. Only then are system actors likely to develop high stakes and a strong interest to keep the anticipated transition pathway on-track. With more and powerful system actors invested in a transition pathway, the path becomes more stable in the face of unforeseen shocks and more likely to recover to its original form and orientation.

The stability of the transition process can be displayed by the stability landscape logic. An influential vision of the future system state is represented as an alternative basin of attraction in the stability landscape. More stability leads to a larger alternative basin of attraction. The basin width acts as a "catchment area" for the goal system state. With a wider basin, more pathways will 
eventually lead to the envisioned system state, and small deviations from the initial transition pathway will have limited influence on the transition outcome. The basin depth reflects the "gravity" of the goal system state: it represents the ease or difficulty to deviate from the envisioned state. The stability of the transition pathway is represented by a halfpipe of attraction that connects the current and envisioned system state. The topography of the halfpipe determines the stability of the transition pathway, analog to the basin of attraction metaphor (Figure 1).

Case explanation: The integration of renewable energy sources has substantially altered the composition of the formerly fossil fuel-based energy system of the EWG region. The incremental nature of the transition has been shown to be a major stabilizing factor. The specific properties of the grid (isolated, but technologically flexible heat distribution grids; nationally integrated electricity grids) together with the step-by-step addition of individual (low-scale) production entities has allowed the system to stably transform while coping with external and internal shocks (e.g., price increase for energy carriers).

On the social side, the main actors that were key figures in the establishment of EWG as a forerunner in the energy transition movement in Austria remained in central positions for many years. This led to a strong regional backing of the transition process, both on a political as well as, more broadly, on a societal level. Central actors in the region remained committed to the support of the transition process, even in times of low(er) social acceptance and support.

On the organizational side, contextually linked to the establishment of the energy region, but organizationally independent, the innovation center "W.E.I.Z." was established in 1997 by the authorities of the city of Weiz. This institution, which aims at initiating energy-related projects, which help drive the regional economy, has gained a nation-wide reputation for its consulting and project-facilitating activities. The regional actors perceive it to be a central cornerstone of the regional transition process toward more sustainable energy use and-at least to a certain extent-also production. In that sense, the innovation center "W.E.I.Z." has substantially contributed by its know-how and leadership in the region to the stability of the energy transition in the region.

Local actors have stressed that, besides attaining the overarching goal of a climate-neutral society (within the commitments of Austria to the Kyoto and COPE-21 goals), the most important motivation to invest in renewables is the potential for the creation of regional economic value, which is associated with the use of regional resources for energy production. This match between regional economic interests and the vision of an energy system based on renewables (including the development of new technological solutions in the region) has led to a broad political backing of the transition by major parts of the society.

\subsubsection{System Resilience}

Along with the stability of the sustainability goals (with the corresponding envisioned system state) and the pathway, we further considered the stability of the system that experiences a transition process; in other words, the resilience of the system in transition. An energy system, for example, needs to keep providing electricity even though it transforms toward renewable energy sources. Ensuring a high level of system resilience during a sustainability transition process minimizes the risk of system-level collapse. Therefore, transition management has to be aware of the basic structures and functions of the system and protect them from collapse during a transition process [13]. In some cases, however, collapse on a sub-systemic scale might be necessary to release potential for innovation and ensure transition progress (e.g., Schumpeters' understanding of creative destruction [55] or the "release" dynamics in the adaptive cycle model [39]). Such a situation can negatively affect the stability of the sustainability transition process. If a disruptive event comes as a surprise to system actors, they might feel excluded from the decision-making process. This can result in perceived "winners" and "losers" coming out of a transition process and lead to a feeling of insecurity and lacking control among system actors. Consequently, their support and commitment for the sustainability transition might fade, which can destabilize the overall process. In order to achieve a stable transition process, 
it is crucial to maintain a high level of system resilience and minimize the negative effects associated with disruptive changes in (parts of) the system.

In the stability landscape metaphor, resilient systems operate within a stabilizing topography, such as a basin of attraction. Extending a basin of attraction into a halfpipe of attraction allows the maintenance of a stabilizing topography at any time during a transition process, while still allowing for transition progress along a stable transition pathway.

Case explanation: The system resilience of the technical infrastructure is supported by the state guarantee for energy security on national and regional levels. Throughout the transition process since the late 1990s, the energy supply in the region has constantly been secured, also in times of high prices or high overall energy demand, by means of energy imports. Independent, regional prosumer networks that could represent a major challenge for the system resilience from a technical point of view (and would require further regulatory interventions) are not possible under the Austrian legislation.

Additional key factors for system resilience have been the stable regulatory framework, which has attributed high importance to the security of energy supplies and the integration of the regional energy system in broader national and international energy networks, which could buffer short-term supply shortages on a regional level. Finally, the constant renewal of the energy infrastructure elements under the lead of the main utility companies in the region has helped to keep the socially-driven demand and the technical infrastructure in line.

The transition of the system up to now is only partial and the danger of the whole system turning back to an unsustainable (fossil-fuel-based) state is not banned. Currently, the regional energy transition is at a critical stage due to decreasing public participation (for example, in the case of insulation refurbishing) and the difficulty of linking the large, international firms in the region to small-scale regional initiatives. Even if bouncing back mechanisms to prior system states are not imminent at the moment, most of the district heating installation could be fired again with coal or gas, requiring rather small adjustments to the infrastructure. The same holds true for electricity production, where the regional production based on renewables could be (at least for the moment and at current process) easily substituted by thermal energy produced outside the region (Table 2). 
Table 2. Stability

\begin{tabular}{|c|c|c|c|c|}
\hline RST Dimension & Analytical Perspective & Relevance for Sustainability Transitions & Stability Landscape Metaphor & Main Aspects in the Energy Region \\
\hline \multirow{2}{*}{ Stability } & Stability of transition process & $\begin{array}{l}\text { The stability of the transition process } \\
\text { determines how the system deals with } \\
\text { uncertainty and recovers from unforeseen } \\
\text { shocks without losing its original sustainability } \\
\text { goals and envisioned transition pathway. }\end{array}$ & $\begin{array}{l}\text { The stability of the goal system state and } \\
\text { transition pathway are determined by the } \\
\text { topography of the goal-basin of attraction } \\
\text { and halfpipe of attraction. }\end{array}$ & $\begin{array}{l}\text { Moderate speed and incremental character of the change process in the region. } \\
\text { Creation of specific institutions, such as the "W.E.I.Z." energy center. } \\
\text { Commitment of a broad coalition of central actors to the goal of renewable } \\
\text { energy production in the region. } \\
\text { Congruence of regional economic and ecological interests for propulsion of } \\
\text { renewable energy production. }\end{array}$ \\
\hline & System resilience & $\begin{array}{l}\text { System resilience is crucial to maintain the } \\
\text { basic structures and functions of the system } \\
\text { that otherwise could be negatively affected by } \\
\text { disruptive events or system-level collapses. }\end{array}$ & $\begin{array}{l}\text { System resilience is determined by the } \\
\text { topography of the stability landscape } \\
\text { surrounding the current system state. }\end{array}$ & $\begin{array}{l}\text { Regulatory requirements ensure energy security. } \\
\text { Openness of the system allows for energy imports to complement regional } \\
\text { energy sources. } \\
\text { Stable regulatory frameworks and the integration in national and international } \\
\text { energy networks are key resilience factors } \\
\text { Possibility to substituter renewable with non-renewable energy sources } \\
\text { allow-at least in principle-a bouncing back of the system to a less } \\
\text { sustainable state. }\end{array}$ \\
\hline
\end{tabular}




\subsection{Adaptability}

\subsubsection{Adaptive Capacity}

So far, we addressed the progress of sustainability transition processes and aspects that determine its stability in the face of shocks and uncertainty. A third major point we considered when conceptualizing sustainability transitions was adaptability, i.e., the extent to which the transition process can be adapted, if necessary. Changing boundary conditions for the sustainability transition, such as market developments, shifting political priorities, changing societal norms and values, or technical innovations, can open up new possibilities for the sustainability transition. The system in transition needs to address these new situations and to respond in a way that supports the sustainability transition process. Thereby, a newly emerging situation could be assessed as a threat for the original ideas of the sustainability transition. This would require a sufficient degree of stability to be capable to deal with the threat and recover to the original sustainability transition goals and pathway. Then again, the same situation could also be perceived as a window of opportunity to reach an even higher state of sustainability, solve existing problems, or accelerate the process. In the second case, adaptations of the sustainability transition process become necessary. Adaptive capacity among system actors ensures that adaptations in the sustainability transition goals (e.g., adapted vision) and pathway (e.g., adapted strategy and actions to reach to vision) can be identified, critically reflected in an integrative process, and consensually (as much as possible) decided upon. The amount of adaptive capacity in a system depends on multiple aspects, such as the governance structures, institutionalized and informal exchange among actors, and transition management activities [56].

Case explanation: With changing market dynamics (amongst others due to the overproduction of renewable energy in Germany), regulations (opening up to micro-grids) and technological developments (digitalization), new challenges with regard to the adaptive capacity of the regional energy system are emerging. At the same time, opportunities for the actors in the regional energy system are presented. Increasing numbers of individuals produce their own energy, transitioning from energy consumers to energy prosumers. This calls for new ways of planning for energy production and consumption. With digitalization fully unfolding, decentralization and smart grid solutions are increasing, and should allow for a higher flexibility of the grid on a regional level. In this context, the importance of electro-mobility increases, too, which allows storing surplus energy in the region that is available for use when the demand is high.

A number of platforms have been created in the region, directed at the exchange of ideas and the bottom-up development of energy-related projects on different scales. A problem with respect to building and sustaining adaptive capacity in the region is the dominant role of public entities-and especially the communities-in these platform organizations. Aside from periodic events hosted by AEE Intec, which have seen their attendance decline over the last years, most formats have been public-sector driven and have often addressed the question of how to attribute public funding to different projects in the energy sector in the region. Industry as well as broad parts of civil society have only been loosely tied into the debate on where the (transition) path should lead.

\subsubsection{Lock-In}

The adaptability of a sustainability transition process can be negatively affected by pathway lock-ins. To this end, we considered the path dependency of transition pathways, i.e., how strongly past developments pre-determine the future evolution of systems $[57,58]$. Path dependency can lead to planning security and stability against external shocks but also to sub-optimal system state outcomes or policy and pathway lock-ins [59-62]. Consequently, the adaptability of the sustainability transition process depends on the relation between adaptive capacity among system actors and existing pathway lock-ins. In that sense, adaptability is linked to the stability of a transition process. An obsolete envisioned system state can still command a high level of attraction (e.g., due to written agreements or conservative mindsets), preventing the system from adapting to altered boundary 
conditions. A transition pathway's stability (e.g., due to inert governance systems or already-executed investments and activities) can hinder adaptations and cause transition pathway lock-ins. Only if an adequate relationship of stability and adaptability exists within a sustainability transition process, system actors can benefit from the positive effects of path dependency (stability), while preventing the negative ones (lock-ins).

Case explanation: From the beginning, there has been a clear focus on solar heat and energy from biomass in EWG, amongst others, due to the activities by the members of the group who initiated the energy transition process in the EWG region at the end of the 1980s. This development was driven both by the technological interest of the members of AAE Intec at that time, and the possibility of receiving funding from the EU level for solar heat projects, as well as by the abundance of biomass resources in the region. At least at the beginning of the transition, alternative development-paths were neglected, and these were only selected once new actors (urban utility companies, industry players) entered the discussion and introduced novel views and solutions.

The measures that have implemented follow, in most cases, a traditional logic and development path of central utility companies producing and distribution energy to consumers, where alternative set-ups of the energy system, e.g., by a stronger integration of prosumer-networks, have been widely neglected (Table 3). 
Table 3. Adaptability.

\begin{tabular}{|c|c|c|c|c|}
\hline RST Dimension & Analytical Perspective & Relevance for Sustainability Transitions & Stability Landscape Metaphor & Main Aspects in the Energy Region \\
\hline \multirow[t]{2}{*}{ Adaptability } & Adaptive capacity & $\begin{array}{l}\text { The adaptive capacity of system actors } \\
\text { determines whether they are capable to identify, } \\
\text { critically reflect, discuss, and consensually } \\
\text { decide upon adaptations of the sustainability } \\
\text { transition process (goals or transition pathway), } \\
\text { if boundary conditions change. }\end{array}$ & $\begin{array}{l}\text { Adaptive capacity reflects the capacity of } \\
\text { system actors to change the position of the } \\
\text { envisioned alternative basin of attraction or the } \\
\text { form/pathway of the halfpipe of attraction. }\end{array}$ & $\begin{array}{l}\text { New energy sources, technologies, and market structures } \\
\text { have to be integrated in the further design and } \\
\text { implementation of the transition. } \\
\text { The strong public involvement represents a challenge for a } \\
\text { dynamic evolution of the exchange platforms in the region. }\end{array}$ \\
\hline & Lock-ins & $\begin{array}{l}\text { Lock-ins are an extreme form of stability that can } \\
\text { cause a very narrow and rigid conception of the } \\
\text { transition process and prevent necessary } \\
\text { adaptations. }\end{array}$ & $\begin{array}{l}\text { Lock-ins appear in the stability landscape as } \\
\text { very deep structures with high resistance. }\end{array}$ & $\begin{array}{l}\text { Strong focus on solar heat and biomass sets limits to the } \\
\text { further development of the regional energy system. } \\
\text { Distinction between producers and consumers could } \\
\text { become obsolete because of decentralized } \\
\text { production/digitalization. }\end{array}$ \\
\hline
\end{tabular}




\section{Discussion}

\subsection{RST and Transition Phases}

The RST concept can assist with understanding transition dynamics and characterizing the resilience of a sustainability transition independent from the current phase of the transition. Still, the constellation of factors that determine a resilient transition process might vary between different transition phases. Consequently, the three RST dimensions shift in terms of how important or critical they are for the analysis of the resilience of a sustainability transition process. We discuss the importance of the RST dimensions along four ideal-typical transition phases: predevelopment, take-off, acceleration, and stabilization [6].

An RST-based analysis in the predevelopment phase should pay particular attention to the transition progress dimension. The success of a sustainability transition in the predevelopment phase depends on whether or not the system is able to reach the take-off phase and start to change its current state [63]. This is only possible if the relation between transition drivers and resistance develops in a way that facilitates system change. Stabilizing aspects have yet to develop, which makes it relatively easy to abandon sustainability goals and ideas about potential pathways toward these goals in the predevelopment phase of the transition process. Without strong drivers that push the system through initial regime resistance, the sustainability transition process might fail before it has an impact on the current system state.

Once the transition process starts and enters the acceleration phase, aspects that stabilize the process gain importance. These are key to put and keep the transition process on track and prevent bouncing-back mechanisms that pose a risk especially in the beginning phases of a transition process. Old system structures still exist and provide an easy alternative to the potentially long and costly transition process. Large parts of the system structures have not yet changed, which makes the transition process particularly vulnerable to unforeseen events or crisis. Hence, an RST-based analysis should pay special attention to the stabilization of the transition process in the beginning of the acceleration phase.

Toward the later part of the acceleration phase of a sustainability transition, the focus of an RST-based analysis should shift more toward the adaptability dimension. The longer the transition process lasts, the more system structures (resources, institutions, regulations, etc.) change along the current transition pathway, which causes path dependency. In consequence, a fundamental re-orientation of the transition process becomes less likely, which makes it easier for system actors to anticipate the future development of the system. However, this can lead to a rigid and narrow conception of the transition process in the form of pathway lock-ins and prevent adaptations to newly emerging opportunities for sustainable development. Identifying and avoiding such lock-ins becomes particularly important during the later phases of the transition process, when path dependencies become increasingly dominant. Therefore, an RST-based analysis that occurs in the later part of the acceleration phase of a sustainability transition process needs to focus on the adaptability of the sustainability transition process.

During the stabilization phase of a sustainability transition process, the creation of system state stability is key. Building system resilience and fading out the transition process are crucial to facilitate the stabilization of a new system state and (preliminarily) end the transition process. This is associated with shifting the focus of a potential analysis from the transition process to the resilience of the new system state. For this reason, an RST-based analysis of the stabilization phase should focus on the system resilience aspect of the stability dimension.

Figure 2 displays the ideal-typical importance of the RST dimensions for the analysis of a sustainability transition process along different transition phases. The bars in the figure represent the RST dimensions upon which emphasis of the analysis should be placed at the respective transition phase. It is not meant as a prescriptive blueprint but as a graphical heuristic to reflect upon which elements are of critical relevance for the resilience of an ongoing sustainability transition process. 


\subsection{Trade-Offs Within the RST Concept}

In this section, we reflect on how the RST dimensions relate to each other and address three major trade-offs. Addressing each RST dimension independently can reduce the explanatory power of the RST concept. In fact, cross-dimension interactions can significantly influence the resilience of a sustainability transition process. Being aware of trade-offs associated with changing RST constellations helps to identify the proper balance between progress, stability, and adaptability, which lead to a resilient sustainability transition process.

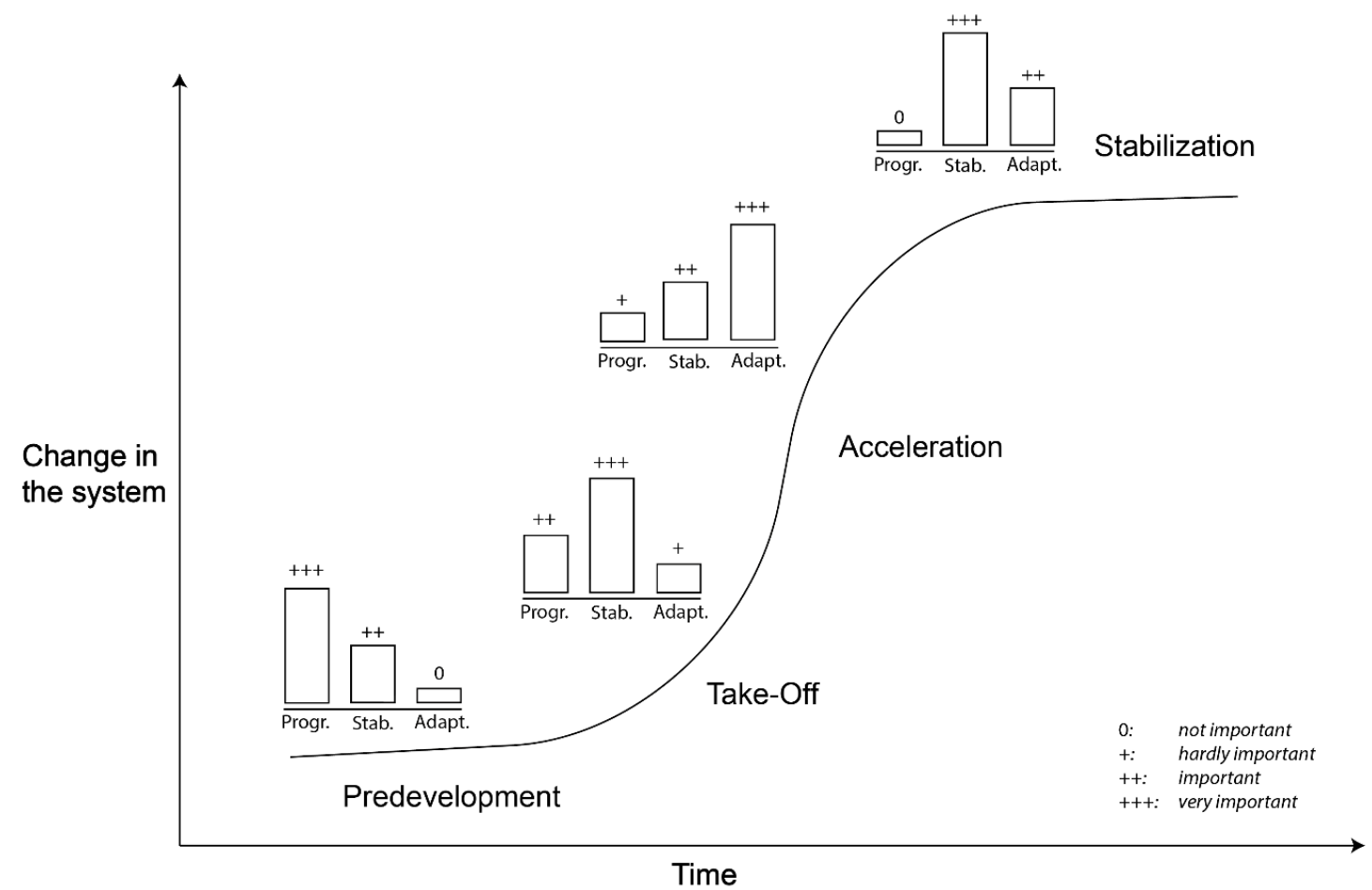

Figure 2. Importance of Resilience of Sustainability Transitions (RST) dimensions across transition phases.

\subsubsection{Progress vs. Stability}

The first trade-off is the relationship between progress and stability. Isolating progress in a transition analysis would lead to a simple efficiency logic, i.e., more progress leads to a more efficient process. An analog transition management approach focuses primarily on radical interventions in the system to ensure a fast and efficient transition. Such disruptive events, however, can have adverse consequences on the overall stability of the transition process. Radical system-level changes can negatively affect the resilience of the system in transition, since they require system changes at a deeper, more fundamental level. This usually affects the system as a whole. Consequently, many system actors need to react and adapt at the same time, which can result in a chaotic, hardly manageable process. This lack of control makes the system more vulnerable to unforeseen events and shocks and increases the risk of a system-level collapse. The short time to adapt to new system structures in a fast-paced transition can overwhelm system actors, create insecurity, and lead to a perceived lack of control. In consequence, system actors might start to doubt the sustainability transition process and lose their commitment to the original sustainability goals and transition pathway. A resilient transition process aims to minimize the negative consequences of disruptive events or interventions while still ensuring a constant and secure progress of the transition at a reasonable pace. 


\subsubsection{Adaptability vs. Stability}

Stability and adaptability share a similar trade-off relationship as progress and stability, since they both can negatively affect each other. A stable sustainability transition process is crucial to protect the original vision and transition pathway against shocks and disturbances. However, in extreme forms, process stability can also hinder re-orientations of the transition when new opportunities emerge. System actors that are too preoccupied with the anticipated process might overlook or even actively work against potential adaptations of the transition process.

Adaptations of the transition process can also have a disruptive influence on the stabilization of a sustainability transition process. Building up identification processes and commitments to stabilize a sustainability transition requires time and a clear and well-communicated vision. Questioning this vision and starting a new, extensive discussion about re-orienting the original ideas of the sustainability transition every time a minor change in the system context occurs interrupts the stabilization process. In consequence, system actors might develop doubts about the longevity of the envisioned process and hesitate to fully commit.

As such, only a proper balance between stability and adaptability allows a stable and flexible transition process that is resilient. Transition management activities that aim for a resilient transition process should focus on stabilizing the current sustainability transition process, while still being sensitive to newly emerging situations. This is associated with assessing a potential adaptation of the transition process in terms of its expected benefits and its negative effects on the process stability.

\subsubsection{System Resilience vs. Bouncing-Back Risk}

This trade-off addresses the reinforcing relationship between a high level of system resilience and bouncing-back risks. Above, we elaborated how an incremental, non-disruptive process can support a high level of system resilience and stability. However, retaining old system structures also lowers the barriers (costs, effort, etc.) to return to a previous state, potentially making it an attractive alternative if the transition progress falls short of expectations or in times of high uncertainty or crisis. This applies even more if sunk investments and the (technical and social) infrastructure of previous system states still exists. A bouncing-back scenario results from such a situation, if the system returns to a previous state and reverses the direction of the transition. The risk of bouncing-back primarily depends on the cost-benefit ratio of returning to the old system state compared the expected cost-benefit ratio of continuing the transition process. To reduce bouncing-back risks, an RST-based transition management approach has to create a stable vision of the transition process that is attractive enough to withstand shocks and crisis, but also make sure that going back to previous system states is not a viable option. In this sense, a resilient sustainability transition process is as incremental as possible, while still being disruptive enough to lower the risk of bouncing back. Phasing out governance can create coexisting strategies to compensate for losses that accompany disruptive transitions and reduce bouncing back risks without necessarily endangering the resilience of the system [31].

\section{Conclusions and Further Development}

In this paper, we introduced a theoretical conceptualization of sustainability transitions that integrates transitions (transition progress) and resilience (stability and adaptability) thinking. The resilience of sustainability transitions concept (RST) provides a theoretical perspective that allows the conceptualization of sustainability transitions as resilient processes that progress in a stable and adaptive manner. Such processes facilitate fundamental system transformations while allowing for procedural stability, management of uncertainty, provision of planning security and prevention of adverse consequences from disruptive changes.

Shifting the focus to the overall transition process itself as a procedural entity of analytical interest, we developed three dimensions of the resilience of the transition process that are essential for the success of a goal-oriented sustainability transitions: (1) progress, as a result of the relation between 
transition drivers and resistance; (2) stability, determined by the stability of the envisioned system state (sustainability goals), the transition pathway, and the resilience of the system in transition; and finally (4) adaptability, depending on the adaptive capacity of system actors and pathway lock-ins.

To verify and highlight our concept, we used the RST dimensions as an analytical lens for an energy transition case study. In the EWG region, the critical mass of actors with an open view on innovation and the willingness to be involved in the transition process, both from a political and a technological point of view, have enabled the transition and led to the required transition progress early on in the transition process. After a first period of grass-roots initiatives, the formalization of specific transition goals and the institutionalization of a public body which was in charge to boost the energy transition and acquired additional federal and European funding, helped stabilize the transition and supported the system in maintaining its progress. The involvement of actors with different political backgrounds and different socio-political agendas allowed broadening the scope of the transition, while ensuring support in the local population. Currently, there is a danger of a lock-in in the sense that the supporters of the transition have problems in reaching out to further actors not yet involved, leading to resistances in terms of extending and scaling the transition progress and scope.

Overall, we confirmed that the theoretically-derived factors shaping the progress, stability, and adaptability of the transition process were highly relevant and useful for this application context. Re-thinking the energy transition in the EWG based on the RST concept helped us to identify and understand the critical elements that influence the dynamic development of the transition process and potentially determine whether the energy transition process in the EWG will be successful, or not.

We used the insights gained from the energy transition case to create a proposition for a more general operationalization of the RST-dimensions (Appendix A). This operationalization creates a bridge between theoretical reflection and empirical reality. In this sense, it can serve as starting point for future RST applications.

As a next step, we call for further operationalization of the RST dimensions in order to develop an RST-based framework as an analytical tool which can be applied to sustainability transitions in a broad variety of contexts. Once fully operationalized, RST thinking can help improve sustainability assessment practices by elucidating the dynamic elements that determine the resilience and, thus, the success of sustainability transitions. Furthermore, RST thinking can improve the knowledge base for sustainability-related decision making, considering the dynamic elements shaping the process of sustainable development. Subsequent management activities could aim at creating a resilient sustainability transition process resulting from the proper balance between transition drivers (e.g., supporting innovation), transition process stability (e.g., fostering commitment to the sustainability goals among system actors), and adaptability (e.g., facilitating continuous monitoring, reflection, and discussion of the sustainability transition process).

Author Contributions: Conceptualization, T.S. and R.W.; Methodology, T.S. and R.W.; Formal Analysis, T.S.; Investigation, T.S. and R.W.; Resources, T.S.; Data Curation, T.S.; Writing-Original Draft Preparation, T.S. and R.W.; Writing-Review \& Editing, T.S., R.W. and C.R.B.; Visualization, T.S.; Supervision, C.R.B.; Funding Acquisition, C.R.B.

Funding: This research is part of the project "ZiFoNE—Civil Society and Research for Sustainable Development" and was funded by the Ministry for Science and Culture of Lower Saxony/Germany. The authors R.W. and C.R.B. acknowledge additional funding by Swiss Mobiliar as part of the funding of the Chair in Urban Ecology and Sustainable Living at EPFL.

Acknowledgments: We thank Susan Mühlemeier for valuable feedback and discussions and Gianluca Cascone for his support in creating Figure 1.

Conflicts of Interest: The authors declare no conflict of interest. 


\section{Appendix A.}

Operationalization of the RST concept.

\begin{tabular}{|c|c|c|c|c|c|}
\hline \multicolumn{2}{|c|}{ Progress } & \multicolumn{2}{|c|}{ Stability } & \multicolumn{2}{|c|}{ Adaptability } \\
\hline Drivers for System Changes & Resistance against System Changes & System Resilience & Stability of the Transition Process & Adaptive Capacity of System Actors & Lock-Ins and Path Dependencies \\
\hline $\begin{array}{l}\text { Creativity for innovations of system actors } \\
\text { (poineeers, hange agents) } \\
\text { Priorities in decision making processes (political, } \\
\text { economic, institutional) } \\
\text { Potential for technological development } \\
\text { (infrastructure, artifacts, socio-technical niches) }\end{array}$ & $\begin{array}{l}\text { Barriers related to actors (conservative } \\
\text { mindsets, dominant routines, rigid networks) } \\
\text { Barriers related to governance (conservative } \\
\text { rules, strict hierarchies, obsolete plans / /isions) } \\
\text { Barriers related to technology development } \\
\text { (effort to learn new skills) } \\
\text { General costs related to system structure } \\
\text { changes (governance, actors, } \\
\text { technology, infrastructure) }\end{array}$ & $\begin{array}{l}\text { Consideration of uncertainty and risks } \\
\text { in the governance system } \\
\text { Capacity of system actors to manage } \\
\text { and recover from unforeseen events } \\
\text { Prevention of bouncing } \\
\text { back mechanisms }\end{array}$ & $\begin{array}{l}\text { Existence of a concrete, clear, and accepted } \\
\text { vision of a future state } \\
\text { Commitment of system actors to } \\
\text { common vision } \\
\text { Expected benefits from the envisioned state } \\
\text { Perceived feasibility of actions necessary to } \\
\text { reach the envisioned state } \\
\text { Cost-benefit ratio of taking action and follow } \\
\text { the transition pathway }\end{array}$ & $\begin{array}{l}\text { Institutionalized structures to reflect, discuss, } \\
\text { and decide upon new developments } \\
\text { Capacity and willingness of system actors to } \\
\text { constantly monitor and re-assess the } \\
\text { transition process }\end{array}$ & $\begin{array}{l}\text { Formal agreements for long time-spans } \\
\text { Existing contracts } \\
\text { Amortization of financial investments } \\
\text { Powerful and tenacious supporters of the } \\
\text { status quo }\end{array}$ \\
\hline
\end{tabular}




\section{References}

1. Bestelmeyer, B.T.; Okin, G.S.; Duniway, M.C.; Archer, S.R.; Sayre, N.F.; Williamson, J.C.; Herrick, J.E. Desertification, land use, and the transformation of global drylands. Front. Ecol. Environ. 2015, 13, $28-36$. [CrossRef]

2. Schandl, H.; Hatfield-Dodds, S.; Wiedmann, T.; Geschke, A.; Cai, Y.; West, J.; Newth, D.; Baynes, T.; Lenzen, M.; Owen, A. Decoupling global environmental pressure and economic growth: Scenarios for energy use, materials use and carbon emissions. J. Clean. Prod. 2016, 132, 45-56. [CrossRef]

3. O'Neill, D.W.; Fanning, A.L.; Lamb, W.F.; Steinberger, J.K. A good life for all within planetary boundaries. Nat. Sustain. 2018, 1, 88-95. [CrossRef]

4. Markard, J.; Suter, M.; Ingold, K. Socio-technical transitions and policy change-Advocacy coalitions in Swiss energy policy. Environ. Innov. Soc. Transit. 2016, 18, 215-237. [CrossRef]

5. Markard, J.; Raven, R.; Truffer, B. Sustainability transitions: An emerging field of research and its prospects. Res. Policy 2012, 41, 955-967. [CrossRef]

6. Rotmans, J.; Kemp, R.; van Asselt, M. More evolution than revolution: Transition management in public policy. Foresight 2001, 3, 15-31. [CrossRef]

7. Rotmans, J.; Loorbach, D. Complexity and Transition Management. J. Ind. Ecol. 2009, 13, 184-196. [CrossRef]

8. Geels, F.W. Ontologies, socio-technical transitions (to sustainability), and the multi-level perspective. Res. Policy 2010, 39, 495-510. [CrossRef]

9. Grin, J.; Rotmans, J.; Schot, J. Transitions to Sustainable Development: New Directions in the Study of Long Term Transformative Change; Routledge: New York, NY, USA, 2010; ISBN 978-1-135-15118-8.

10. Newell, B.; Crumley, C.L.; Hassan, N.; Lambin, E.F.; Pahl-Wostl, C.; Underdal, A.; Wasson, R. A conceptual template for integrative human-environment research. Glob. Environ. Chang. 2005, 15, 299-307. [CrossRef]

11. Young, O.; Lambin, E.; Alcock, F.; Haberl, H.; Karlsson, S.; McConnell, W.; Myint, T.; Pahl-Wostl, C.; Polsky, C.; Ramakrishnan, P.S.; et al. A Portfolio Approach to Analyzing Complex Human-Environment Interactions: Institutions and Land Change. Ecol. Soc. 2006, 11. [CrossRef]

12. Binder, C.R.; Hinkel, J.; Bots, P.; Pahl-Wostl, C. Comparison of Frameworks for Analyzing Social-ecological Systems. Ecol. Soc. 2013, 18. [CrossRef]

13. Binder, C.R.; Mühlemeier, S.; Wyss, R. An Indicator-Based Approach for Analyzing the Resilience of Transitions for Energy Regions. Part I: Theoretical and Conceptual Considerations. Energies 2017, 10, 36. [CrossRef]

14. Loorbach, D.; Frantzeskaki, N.; Avelino, F. Sustainability Transitions Research: Transforming Science and Practice for Societal Change. Annu. Rev. Environ. Resour. 2017, 42, 599-626. [CrossRef]

15. Silva, A.; Stocker, L. What is a transition? Exploring visual and textual definitions among sustainability transition networks. Glob. Environ. Chang. 2018, 50, 60-74. [CrossRef]

16. Fiksel, J. Sustainability and resilience: Toward a systems approach. Sustain. Sci. Pract. Policy $2006,2$. [CrossRef]

17. Geels, F.W. Reconceptualising the co-evolution of firms-in-industries and their environments: Developing an inter-disciplinary Triple Embeddedness Framework. Res. Policy 2014, 43, 261-277. [CrossRef]

18. Folke, C. Resilience (Republished). Ecol. Soc. 2016, 21. [CrossRef]

19. Redman, C.L. Should sustainability and resilience be combined or remain distinct pursuits? Ecol. Soc. 2014, 19. [CrossRef]

20. Walker, B.; Holling, C.S.; Carpenter, S.; Kinzig, A. Resilience, Adaptability and Transformability in Social-ecological Systems. Ecol. Soc. 2004, 9. [CrossRef]

21. Smith, A.; Stirling, A. The Politics of Social-ecological Resilience and Sustainable Socio-technical Transitions. Ecol. Soc. 2010, 15. [CrossRef]

22. Olsson, P.; Galaz, V.; Boonstra, W.J. Sustainability transformations: A resilience perspective. Ecol. Soc. 2014, 19, 1. [CrossRef]

23. Hordijk, M.; Sara, L.M.; Sutherland, C. Resilience, transition or transformation? A comparative analysis of changing water governance systems in four southern cities. Environ. Urban. 2014, 26, 130-146. [CrossRef]

24. Wiese, F. Resilience Thinking as an Interdisciplinary Guiding Principle for Energy System Transitions. Resources 2016, 5, 30. [CrossRef] 
25. Westley, F.; Olsson, P.; Folke, C.; Homer-Dixon, T.; Vredenburg, H.; Loorbach, D.; Thompson, J.; Nilsson, M.; Lambin, E.; Sendzimir, J.; et al. Tipping Toward Sustainability: Emerging Pathways of Transformation. AMBIO J. Hum. Environ. 2011, 40, 762-780. [CrossRef]

26. Enfors, E. Social-ecological traps and transformations in dryland agro-ecosystems: Using water system innovations to change the trajectory of development. Glob. Environ. Chang. 2013, 23, 51-60. [CrossRef]

27. Seeliger, L.; Turok, I. Towards Sustainable Cities: Extending Resilience with Insights from Vulnerability and Transition Theory. Sustainability 2013, 5, 2108-2128. [CrossRef]

28. Galaz, V. Geo-engineering, Governance, and Social-Ecological Systems: Critical Issues and Joint Research Needs. Ecol. Soc. 2012, 17. [CrossRef]

29. Van den Bergh, J.C.J.M.; Kemp, R. Transition lessons from economics. In Managing the Transition to Renewable Energy: Theory and Practice from Local, Regional and Macro Perspectives; Bruinsma, F.R., Idenburg, A., Vreeker, R., van den Bergh, J.C.J.M., Eds.; Edward Elgar: Cheltenham, UK, 2008; pp. 81-127, ISBN 978-1-84720-229-1.

30. Loorbach, D.; Rotmans, J. The practice of transition management: Examples and lessons from four distinct cases. Futures 2010, 42, 237-246. [CrossRef]

31. Loorbach, D. To Transition! Governance Panarchy in the New Transformation; Inaugural Address; Erasmus University Rotterdam: Rotterdam, The Netherlands, 2014.

32. Hess, D.J. Sustainability transitions: A political coalition perspective. Res. Policy 2014, 43, 278-283. [CrossRef]

33. Geels, F.W.; Tyfield, D.; Urry, J. Regime Resistance against Low-Carbon Transitions: Introducing Politics and Power into the Multi-Level Perspective. Theory Cult. Soc. 2014, 31, 21-40. [CrossRef]

34. Foxon, T.J. Technological lock-in and the role of innovation. In Handbook of Sustainable Development; Atkinson, G., Dietz, S., Neumayer, E., Eds.; Edward Elgar: Cheltenham, UK, 2007; ISBN 978-1-84376-577-6.

35. Geels, F.W. Technological transitions as evolutionary reconfiguration processes: A multi-level perspective and a case-study. Res. Policy 2002, 31, 1257-1274. [CrossRef]

36. Suarez, F.F.; Oliva, R. Environmental change and organizational transformation. Ind. Corp. Chang. 2005, 14, 1017-1041. [CrossRef]

37. Geels, F.W.; Schot, J. Typology of sociotechnical transition pathways. Res. Policy 2007, 36, 399-417. [CrossRef]

38. Rip, A.; Kemp, R. Technological Change; Battelle Press: Columbus, OH, USA, 1998; ISBN 1-57477-046-2.

39. Gunderson, L.H.; Holling, C.S. Panarchy: Understanding Transformations in Human and Natural Systems; Island Press: Washington, DC, USA, 2001; ISBN 1-59726-939-5.

40. Fazey, I.; Schäpke, N.; Caniglia, G.; Patterson, J.; Hultman, J.; van Mierlo, B.; Säwe, F.; Wiek, A.; Wittmayer, J.; Aldunce, P.; et al. Ten essentials for action-oriented and second order energy transitions, transformations and climate change research. Energy Res. Soc. Sci. 2018, 40, 54-70. [CrossRef]

41. Kerssens-van Drongelen, I. The iterative theory-building process: Rationale, principles and evaluation. Manag. Decis. 2001, 39, 503-512. [CrossRef]

42. Binder, C.R.; Knoeri, C.; Hecher, M. Modeling transition paths towards decentralized regional energy autonomy: The role of legislation, technology adoption, and resource availability. Raumforsch. Raumordn. 2016, 74, 273-284. [CrossRef]

43. Binder, C.R.; Absenger-Helmli, I.; Schilling, T. The reality of transdisciplinarity: A framework-based self-reflection from science and practice leaders. Sustain. Sci. 2015, 10, 545-562. [CrossRef]

44. Vanwindekens, F.M.; Stilmant, D.; Baret, P.V. Development of a broadened cognitive mapping approach for analysing systems of practices in social-ecological systems. Ecol. Model. 2013, 250, 352-362. [CrossRef]

45. Mühlemeier, S.; Binder, C.R.; Wyss, R. "It's an Endurance Race" An Indicator-Based Resilience Analysis of the Energy Transition in the Allgäu Region, Bavaria. GAIA Ecol. Perspect. Sci. Soc. 2017, 26, 161-224. [CrossRef]

46. Kemp, R.; Loorbach, D.; Rotmans, J. Transition management as a model for managing processes of co-evolution towards sustainable development. Int. J. Sustain. Dev. World Ecol. 2007, 14, 78-91. [CrossRef]

47. Loorbach, D. Transition Management for Sustainable Development: A Prescriptive, Complexity-Based Governance Framework. Governance 2010, 23, 161-183. [CrossRef]

48. Loorbach, D.; Rotmans, J. Managing Transitions for Sustainable Development. In Understanding Industrial Transformation; Olsthoorn, X., Wieczorek, A.J., Eds.; Kluwer Academic Publishers: Dordrecht, The Netherlands, 2006; Volume 44, pp. 187-206. ISBN 978-1-4020-3755-9.

49. Luthe, T.; Wyss, R. Resilience to climate change in a cross-scale tourism governance context: A combined quantitative-qualitative network analysis. Ecol. Soc. 2016, 21. [CrossRef] 
50. Späth, P.; Koblmüller, M.; Kubeczko, K.; Faber, F.; Bärnthaler, J.; Bergmann, H.; Luttenberger, C.; Breisler, A. Energieregionen: Wirksame Leitbildprozesse und Netzwerke zur Regionalen Gestaltung Sozio-Technischen Wandels; BMVIT Berichte aus Energie-und Umweltforschung: Vienna, Austria, 2007; Volume 29, pp. 2008-2010.

51. Späth, P.; Rohracher, H. 'Energy regions': The transformative power of regional discourses on socio-technical futures. Res. Policy 2010, 39, 449-458. [CrossRef]

52. Binder, C.R.; Hecher, M.; Vilsmaier, U. Visionen, Institutionen und Infrastrukturen als Elemente der Energietransformation. In Klima von unten: Regionale Governance und Gesellschaftlicher Wandel; Gill, B., Kropp, C., Böschen, S., Vogel, K., Eds.; Campus Verlag: Frankfurt, Germany, 2014; pp. 267-286.

53. Hecher, M.; Vilsmaier, U.; Akhavan, R.; Binder, C.R. An integrative analysis of energy transitions in energy regions: A case study of ökoEnergieland in Austria. Ecol. Econ. 2016, 121, 40-53. [CrossRef]

54. Verbong, G.; Geels, F. The ongoing energy transition: Lessons from a socio-technical, multi-level analysis of the Dutch electricity system (1960-2004). Energy Policy 2007, 35, 1025-1037. [CrossRef]

55. Schumpeter, J. Capitalism, Socialism and Democracy; Harper \& Brothers: New York, NY, USA, 1942; Volume 825.

56. Engle, N.L. Adaptive capacity and its assessment. Glob. Environ. Chang. 2011, 21, 647-656. [CrossRef]

57. David, P.A. Path Dependence, Its Critics, and the Quest for 'Historical Economics'; Edward Elgar: Cheltenham, UK, 2007; ISBN 978-1-84720-703-6.

58. Martin, R.; Sunley, P. Path dependence and regional economic evolution. J. Econ. Geogr. 2006, 6, 395-437. [CrossRef]

59. Marschke, M.; Berkes, F. Exploring Strategies that Build Livelihood Resilience: A Case from Cambodia. Ecol. Soc. 2006, 11. [CrossRef]

60. Cho, M.; Hassink, R. Limits to Locking-out through Restructuring: The Textile Industry in Daegu, South Korea. Reg. Stud. 2009, 43, 1183-1198. [CrossRef]

61. Pendall, R.; Foster, K.A.; Cowell, M. Resilience and regions: Building understanding of the metaphor. Camb. J. Reg. Econ. Soc. 2009, 3, 71-84. [CrossRef]

62. Nair, S.; Howlett, M. From robustness to resilience: Avoiding policy traps in the long term. Sustain. Sci. 2016, 11, 909-917. [CrossRef]

63. Martens, P.; Rotmans, J. Transitions in a globalising world. Futures 2005, 37, 1133-1144. [CrossRef] 